\title{
Research on the Burnout of High School Teachers Based on Teacher Professional Development
}

\author{
Hongying Qiu \\ College of Education, Fujian Normal University, Fuzhou, China \\ Email: 782984056@qq.com
}

How to cite this paper: Qiu, H.Y. (2018) Research on the Burnout of High School Teachers Based on Teacher Professional Development. Open Journal of Social Sciences, 6, 219-229.

https://doi.org/10.4236/jss.2018.612019

Received: November 26, 2018 Accepted: December 25, 2018

Published: December 28, 2018

Copyright $\odot 2018$ by author and Scientific Research Publishing Inc. This work is licensed under the Creative Commons Attribution International License (CC BY 4.0).

http://creativecommons.org/licenses/by/4.0/

\begin{abstract}
High school teachers are an important part of the national teacher group. However, with the reform and development of education in China, the requirements for teachers are becoming stricter and stricter. Teachers have gradually shown burnout in teaching work, which has seriously affected teaching work and teachers' developing themselves. Therefore, based on the perspective of teacher professional development, this paper analyzes and studies the causes of job burnout in high school teachers through literature analysis, and proposes measures to promote teachers' professional development, reduce burnout and promote teaching quality.
\end{abstract}

\section{Keywords}

High School Teachers, Burnout, Professional Development

\section{Foreword}

The American Teachers Association pointed out in 1983 that teachers are a high-risk group of burnouts and found that $37.5 \%$ of the teachers surveyed had serious burnout. Zhanhui Li also studied teacher burnout and found that $76 \%$ of the teachers surveyed clearly expressed pressure, and about $78 \%$ of teachers had serious job burnout [1]. As a large group of teachers in the country, high school teachers have important significance in discussing whether they have job burnout and promote the professional development of high school teachers and promote the development of education in China. In August 2016, in the "Guiding Opinions on Deepening the Reform of University Teachers' Assessment and Evaluation System" promulgated by the Ministry of Education, it was pointed 
out that the performance of education and teaching as well as the examination of teaching quality and the professional development of teachers should be regarded as important contents of teacher evaluation [2]. It can be seen that the professional development of teachers cannot be delayed. However, in the professional development of teachers, burnout has become an important obstacle. How to reduce the burnout of high school teachers and promote the professional development of teachers is the primary starting point of this paper. From the perspective of teacher professional development, it analyzes the causes of high school teachers' burnout and puts forward effective strategies and suggestions.

\section{Concept Analysis}

\subsection{High School Teacher}

High school teachers include ordinary high school, adult high school teachers, and secondary vocational teachers. In addition to completing the tasks of education and teaching, high school teachers must also gain a sense of self-fulfillment, enhance their professional competence, and promote professional development.

\subsection{Burnout}

Maslach and Pines believe that "people are engaged in the career field of serving people. Burnout is characterized by the failure of individual emotions, the breakdown of personality and the reduction of personal accomplishment" [3]. In 1974, Feldberg first defined the concept of burnout. He believed that "burnout" refers to people who are exhausted due to excessive working hours and high work intensity. Jiangxia Li believes that teacher burnout refers specifically to teachers' long-term stressful atmosphere in their work, work problems and obstacles, which makes teachers have a state of exhaustion about emotions, attitudes and behaviors. In this state, there is often no personality, personal accomplishment is low, and emotions are close to exhaustion [4]. Therefore, it can be concluded that teachers' job burnout is manifested in: First, the mental state is extremely poor, the whole person's consciousness and behavior are in a negative and exhausted manner, and they are not interested in the work; Second, the satisfaction with the work is not high. There is no sense of accomplishment and belonging in the work process; the third is to make people physically and mentally exhausted, especially when they encounter setbacks, which shows physical discomfort and seriously affects work efficiency.

\subsection{Teacher Professional Development}

In the 1966 "Recommendation on the Status of Teachers", UNESCO stated that the profession of teachers is a "professional". Starting from the establishment of the teacher qualification system in 1995, China has shown that professionalization of teachers has taken a crucial step in practice. However, there was no uniform definition of the meaning of "professional development" at that time. Lan Ye believes that "the process of teacher professional development represents the 
professional growth of teachers and the continuous updating, evolution and enrichment of teachers' internal professional structure" [5]. Ningbo Zhu believes that "whether in the pre-service teacher training stage, the teaching stage or the in-service training process, individual teachers must continuously study and research, continuously develop the professional connotation of teachers, and gradually reach the realm of professional maturity" [6]. Wanhai Liu believes that "teacher professional development" is driven by teachers' professional consciousness, with teacher education as the main auxiliary way, and the teacher's professional knowledge and belief system is constantly improving and improving the dynamic development process [7]. Xudong Zhu believes that teachers' professional connotation has three dimensions, including teaching students to learn, educating people, and services. The connotation of teacher professional development includes teacher spirit, teacher knowledge and teacher ability [8].

From the above scholars' expression of the professional development of teachers, it can be known that although the definition of teacher professional development is not uniformly defined, it is all expressed around the professionalism of teachers, such as having mature professional ability and serious professional attitude. The professional emotions, as well as the professional consciousness and initiative of the teachers, can be regarded as professional development.

\section{The Status Quo of Burnout Based on Teacher Professional Development}

From the perspective of teacher professional development, the status quo of teachers' job burnout is mainly reflected in the following aspects:

\subsection{Teachers Are Less Professionally Motivated and Lack Motivation to Learn}

Some teachers are satisfied with the status quo, do not think about progress, the training activities arranged by the school, the class skill competition, the participation of the off-campus teacher exchange activities are not very motivated, the professional knowledge required for teaching is not updated and strengthened, and the teaching habits have been stuck in the previous teaching habits. This is extremely dangerous for their own progress and the growth of their students.

\subsection{The Teacher Is Weak and Does Not Seek Advancement}

The professional development of teachers requires teachers to have serious professional attitudes, full of professional emotions, full of love and curiosity for their profession. However, teachers with burnout often lose their enthusiasm for work because of excessive work pressure or unpleasant interpersonal relationships, and have experienced mental exhaustion earlier. They have no expectation for their work, they have passed, and they have shown a state of extreme disregard for their professional development. 


\subsection{Teacher Pressure Is Too High, Low Sense of Achievement}

High school teachers, especially ordinary high school teachers, have to respond to the student's enrollment rate, as well as high expectations from the society and parents. They must not only be outstanding in teaching ability, but also have excellent class management skills, communication skills, executive ability, etc. it is necessary to develop in an all-round way, to be able to cope with all kinds of outstanding teachers, but in the long run, when teachers face some problems, they are not relieved in time, and it is easy to cause depression and energy fatigue. In addition, the evaluation of teachers in the society is often one-sided. They cannot see the contribution behind them, so many teachers will feel nervous and have a low sense of accomplishment.

\section{Attribution Analysis of Teacher Burnout}

The causes of teacher burnout can be analyzed from many aspects. By analyzing the causes of burnout of high school teachers and understanding the life and work status of teachers, we can work hard to reduce the burnout and propose more targeted suggestions. The specific attribution analysis is as follows:

\subsection{The Student-Teacher Ratio Is Larger Than the Standard Required by the Ministry of Education, and the Teacher's Teaching Pressure Is High, Resulting in Burnout}

Table 1 shows the student-teacher ratio data for high school education from 2013 to 2017 (mainly observing the ratio of students to normal high school and secondary vocational education). According to these data, it can be seen that since 2013, the number of ordinary high school students has gradually decreased, but the overall tends to be stable, the number of teachers is on the rise, the teacher-student ratio tends to be stable but declines in 2017, and one teacher is about 13 students were assigned; the number of students in secondary vocational education showed a decreasing trend, the number of teachers also decreased year by year, the teacher-student ratio showed a decreasing trend, and one teacher was assigned to about 19 students. According to the "Opinions on the Establishment of Standards for the Preparation of Teaching Staff in Primary

Table 1. School-to-teacher ratio of high school students in 2013-2017 (unit: 10,000 people) http://www.moe.gov.cn/s78/A03/moe_560/jytjsj_2017/.

\begin{tabular}{ccccccc}
\hline Years & Total & $\begin{array}{c}\text { Ordinary high } \\
\text { school students }\end{array}$ & $\begin{array}{c}\text { Ordinary high } \\
\text { school teachers }\end{array}$ & $\begin{array}{c}\text { Student-teacher } \\
\text { ratio }\end{array}$ & $\begin{array}{c}\text { Secondary } \\
\text { vocational education } \\
\text { Student at school }\end{array}$ & $\begin{array}{c}\text { Secondary } \\
\text { vocational } \\
\text { education teacher }\end{array}$ \\
\hline 2013 & 4369.9 & 2435.9 & 162.9 & $15.0: 1$ & 1923.0 & 86.8 \\
2014 & 4170.7 & 2400.5 & 166.3 & $14.0: 1$ & 1755.3 & $23.0: 1$ \\
2015 & 4037.7 & 2374.4 & 169.5 & $14.0: 1$ & 1656.7 & 85.8 \\
2016 & 3970.1 & 2366.7 & 173.3 & $14.0: 1$ & 1599.0 & 84.4 \\
2017 & 3971.0 & 2374.5 & 177.4 & $13.0: 1$ & 1592.5 & 84.0 \\
\hline
\end{tabular}

Note: The data is from the Ministry of Education website. 
and Secondary Schools", the ratio of students to teachers in ordinary high schools is $12.5: 1$, the ratio of students to teachers in the county is $13: 1$, and the ratio of rural students to teachers is 13.5:1 [9]. That is, the total is between 12.5 and 13.5; according to the "Setup Standards for Secondary Vocational Schools", the ratio of students to teachers in secondary vocational schools should reach 20:1 [10]. From this, it can be concluded that the student-teacher ratio is still larger than the standard, and the pressure on the teacher will be too large in the undertaking and responsible student's academics, which will also strengthen the teacher's sense of job burnout.

\subsection{Teachers' Wages Are Generally Low and Their Work Motivation Is Weak}

In addition to the fixed base salary, high school teachers' wages also include performance pay. Performance pay is distributed differently for teachers with different abilities. Therefore, the overall level of basic wages is mainly considered. After analyzing and analyzing the statutory wages of high school teachers in 31 countries of the OECD, Qiang Yu found that the average salary of high school teachers in China was 1.05 times of the national wage, which was lower than the reasonable level [11]. In addition to the fixed base salary, high school teachers' wages also include performance pay. In remote and impoverished areas, high school teachers have lower wages, and the principle of "more work and more" cannot be quantified in the school system. The salary increase of teachers is also slow. Due to the large number of teachers in the country, the reform of teachers' wages also has a long way to go. Therefore, low wages, general benefits, and high-stress teachers with high mental stress do not have the motivation to improve their own deficiencies, improve their professional ability, and learn communication skills. Therefore, teachers choose a comfortable state and are not comfortable in the comfort zone. If you leave, you will not be able to cope with various challenges and have insufficient motivation.

\subsection{The Unity of Teacher Evaluation Makes Teachers' Work Achievement Low}

In the evaluation of teachers in China, the reward and punishment system that attaches importance to management occupies a guiding position. The main concern is the scores of teachers before the evaluation. It is a kind of summative evaluation to evaluate teachers as a standard. Therefore, in order to achieve good results at the end of the period, teachers achieve excellent evaluations, often pursue student achievement, and do not pay attention to the development of other aspects of students [12]. Regardless of the type of high school, the teacher's evaluation system is mostly based on the student's test scores. The student's knowledge output is displayed on a single transcript. The student's test score seems to determine the only way to evaluate the teacher's work standard. Teachers only put all their energy into improving students' performance. The reality is that teachers' pay and return are not proportional. No matter how much effort 
the teachers put, there will always be students' grades not improving, and teachers' work enthusiasm will be lower and lower. The sense of burnout is getting stronger and stronger.

\subsection{Double Pressure of Administration and Teaching}

Some teachers not only have to take administrative positions but also are busy with teaching. For example, they also serve as class teachers and single-student teachers. Therefore, teachers must not only take care of students' academics, prepare teaching plans, but also conduct class management and work intensity. In addition, most high school students are in adolescence, have autonomy, have rebellious psychology, management needs to cooperate with teachers' communication skills, as well as knowledge of various disciplines of psychology and management. In addition to preparing lessons, teachers should regularly visit the students' homes to learn about the students' situation. In the evening, they should go to the classroom for supervision. Such long working hours and work intensity make the teachers in high-load operation, and the teachers are prone to emotional and psychological problems. Fatigue, feeling mental fatigue.

\subsection{Pressure from Parents, Schools and Society}

Xiuyu Yang and others believe that most countries have high expectations for their own education, education is placed in a pivotal position, and the expectations of front-line teachers who undertake education and teaching work are naturally high, and the values are followed. Increasingly diversified, the expectations of teachers from all walks of life and schools and at home are not the same [13]. For parents and schools in ordinary high schools, the rate of enrollment is the most important. Only when the student's grades are at the forefront, the students can be admitted to key universities, and the school can attract excellent teachers and students. Therefore, this important task is on the teachers. Their relationship with the students is the closest and direct, but also this will make the teacher's psychological burden heavy. Under such a depressed working atmosphere, the teachers are physically and mentally exhausted, which seriously affects the teaching work.

\subsection{Unsatisfactory Communication Leads to Unpleasant Working Atmosphere}

A survey of newly recruited teachers in Denmark found that teachers entering the new school and the new environment will face communication and exchanges with other teachers, principals, administrators and other personnel. They found that dealing with relationships between teachers is even more difficult and important than serving students. Hongqiang $\mathrm{Hu}$ and others have also found through research that teachers, when they first enter the job, are often overwhelmed in the face of school emergencies due to lack of experience and teaching practice, and often have to deal with complex interpersonal relationships, and teachers' personal accomplishment is greatly reduced. Energy is con- 
sumed [14]. It is not difficult to imagine that in a small society such as a school, teachers need to spend time and energy and communicate strategies to deal with all aspects. If the teacher suffers from long-term exclusion and is unhappy with colleagues around him, it is conceivable that the state of the teacher is definitely negative, there is no sense of accomplishment in the work, and the motivation of the work is lost, resulting in burnout.

\section{Job Burnout Strategies Based on Teacher Professional Development}

To achieve the goal of promoting the professional development of teachers, we can promote the change of the phenomenon of job burnout of high school teachers from the perspective of teachers and schools. The first is the teacher's coping strategy:

\subsection{Establish the Concept of Lifelong Learning and Improve the Sense of Autonomy in Professional Development}

Teachers can only continue to develop professionally if they continue to learn and do not relax their requirements. In the rounds of curriculum reform, teachers are required not only to teach students to learn, but also to teach students how to learn. Therefore, high school teachers who are under great teaching pressure should constantly improve teaching methods in practice teaching and create the teaching style, improve teaching skills, and teach students of different traits in accordance with their aptitude. Therefore, teachers should constantly learn new knowledge and learn new ideas to be enriched into practical teaching. Through lifelong learning, teachers can keep up with the pace of development of the times and give students new experiences continuously in order to apply a new round of teaching and learning changes. Otherwise, without new knowledge, teaching ability will decline, teachers will not have self-confidence and ability to go. In response to the teaching situation in the long run, teachers are prone to slackness and lack of sense of accomplishment, thus resulting in burnout. In the process of teaching, teachers also need to improve the sense of autonomy in professional development . They often do not have a clear personal development plan, whether it is near-term planning or medium and long term planning. Therefore, in the unplanned work, it is easy to be burned out of the profession, and the state of indifference is not conducive to the professional development of teachers. Therefore, teachers can formulate career plans according to their specific conditions and personal characteristics, accurately locate, continuously improve and develop, and ultimately improve the sense of autonomy of professional development.

\subsection{Pay Attention to Your Mental Health and Create Good Interpersonal Relationships}

Faced with different personalities, teachers with different characteristics often face tremendous pressure. They are prone to bad emotions when dealing with 
behaviors such as absenteeism, fights, and defeats. Teachers also take great pressure on students who face problems. The educational transformation of students on these issues is a difficult and long-term process. Teachers need to be sincere, persistent, trusting students, and helping students in the actual life and study of students. Therefore, first of all, teachers should maintain a normal mindset. They should not give themselves too much pressure. They should face up to the students' problems and admit that this is normal. Secondly, they should find ways to solve problems and find suitable debugging methods, such as Exercise, communicate with colleagues, listen to songs, etc., to make your mind calm and relaxed.

\subsection{For Secondary Vocational Teachers, You Can Improve Your Job Burnout by Enriching Your Professional Skills and Improving Your Professional Skills}

Teachers often feel anxious and nervous because of lack of professional ability or teaching ability. They are more and more afraid of work and have a low sense of self-fulfillment. Therefore, we must solve it fundamentally. In view of the characteristics of the "double teacher quality" of vocational education teachers, in addition to the general quality requirements, vocational education teachers must also have strong professional and technical ability and practical teaching ability. You can improve your comprehensive ability, especially technical ability and teaching ability, by participating in training courses organized by schools, exploring in teaching practice, learning from excellent teachers and peers, or learning online courses. Only if you are strong, your heart is full of energy, strong and confident, you will show great satisfaction and self-confidence in your work, and burnout will disappear.

The second is the school's coping strategy:

\subsection{Adhere to "People-Oriented" and Advocate Democratic Management Methods}

The school is about the human system. Through the management of people to achieve the purpose of cultivating people and developing people [15]. Using the "people-oriented" management theory to guide school management, especially in dealing with teachers' job burnout, we can effectively stimulate teachers' work and reduce burnout from the perspective of teachers. Teachers are important school members and play an important role. School management should adopt the concept of "people-oriented" to recruit teachers into the school management team, and fully absorb the teachers' suggestions for campus construction, student management, education and teaching, so that teachers can fully recognize their own subject status, subjective consciousness, and individual ability. Encourage teachers to continuously improve and develop, enhance their own abilities, let teachers feel a sense of responsibility and sense of accomplishment, have strong self-confidence to cope with difficulties, and when there is a state of job burnout, promptly recognize the problem and correct it in time. 


\subsection{Diversified Teacher Evaluation Methods}

The way schools evaluate teachers is through the students' academic achievements, but in the process of teaching and managing students, teachers often pay more effort, higher work intensity, but the results are not satisfactory. Therefore, the school should stand in the position of the teacher and provide teachers with a variety of evaluation methods. The teacher's academic performance can be comprehensively assessed through teacher-to-teacher mutual evaluation, principal evaluation, teacher skill competition, and training course performance. Quantitatively analyze the work of teachers and give material and spiritual rewards to teachers who perform well.

\subsection{Reduce the Administrative Pressure of Teachers and "Burden the Burden" for Teachers}

Teachers are often caused by mental stress and lack of motivation to work together. Therefore, in order to make teachers reduce their sense of job burnout, it is necessary to "burden the burden" for teachers, especially the administrative pressure of teachers. In high school, teachers not only have to undertake teaching work, but also undertake duties such as class teacher and grade leader. After class, in addition to preparing lessons, they also have to attend various meetings of the school. They are often too busy and have no time to arrange self-development and self. Improvement, and even in this process, derived the idea of resignation. Therefore, the school should reasonably arrange the administrative work of the teachers, appropriately depress the teachers, and do not over-range the teachers with more tasks as the main managers.

\subsection{Carry out Training Aimed at Promoting the Professional Development of Teachers}

Schools should actively organize various training activities to provide teachers with a platform to learn and show themselves. The teacher's job is to complete the teaching task, help the students to grow and promote their professional development, but the teacher's time is often occupied by the teaching tasks, so there are few opportunities and time to learn. The school should fully consider the difficulties faced by the teachers and choose suitable teachers. The development of training courses allows teachers to learn advanced teaching concepts and diverse teaching methods, so that teachers can reflect on their behavior and improve in the process of training, improve knowledge structure and improve practical teaching ability. Through this, the school can improve the quality of the entire teaching team and play an important role in the education and teaching of the school.

\subsection{Advocate "Respecting Teachers and Teaching" to Create a Good Interpersonal Environment}

The school should give teachers enough space for individual development and 
retain a unique teaching style to guide students to correctly recognize the role of teachers and the professional prestige of teachers. Through various activities such as Teacher's Day, Science and Technology Festival and other important days, students can express their gratitude and respect to the teachers and enhance the feelings of students and teachers. There must also be a certain amount of communication space between the faculty and staff to organize their interactions, such as faculty and staff games, teaching skills competitions, and school performances to promote communication. Schools should try to reduce the burden on teachers, that is, reduce the pressure and burden on teachers, arrange teaching work reasonably, and let teachers have time to relax. In addition, teachers should pay full attention to the personal situation of teachers to help teachers who have difficulties in life, work and psychology. If teachers live and work in a pleasant and relaxed atmosphere, their psychological stress and tiredness will be relieved.

\section{Conclusion}

It can be seen from the above analysis that teachers' job burnout has many attributions, and in the face of job burnout, teachers often show helplessness and are unmoved. Some high school teachers do not even realize that they have burnout status. In the face of independent individual students, teachers are physically and mentally exhausted, and their mental state is extremely nervous, but they do not know how to change this situation. Therefore, this article explores how to reduce the teacher's job burnout from the perspective of teacher professional development, and puts forward targeted suggestions from the teacher level and the school level. The most important one is the efforts that the teachers themselves should make, such as enriching themselves; learning; improving professional skills; improving teaching skills; learning the theoretical knowledge of other disciplines to apply to daily work; dealing with the interpersonal relationships between teachers, students and teachers, letting their mental state rejuvenate and be full of hope for life. The professional development of teachers provides a solution path for teachers' job burnout, and ultimately promotes the development of the school and the progress of students.

\section{Conflicts of Interest}

The author declares no conflicts of interest regarding the publication of this paper.

\section{References}

[1] Li, Z.H. and Wei, L. (2013) Reasons and Countermeasures of College Teachers' Job Burnout-A Survey from Hebei Province. Chinese Adult Education, No. 11, 43-45.

[2] He, J.H. and Dang, H.X. (2017) Exploration and Practice of College Teacher Teaching Development Based on Teacher Professional Development. University Teaching in China, No. 9, 85-90.

[3] Malach-Pines, A. (2005) The Burnout Measure, Short Version. International Journal of Stress Management, 12, 78-88. https://doi.org/10.1037/1072-5245.12.1.78 
[4] Li, J.X. (2003) Research on the Relationship between Teacher Burnout and Teaching Effectiveness. Tianjin Normal University, Tianjin.

[5] Ye, L. (2001) A New Exploration of Teacher Role and Teacher Development. Education Science Press, Beijing.

[6] Zhu, N.B. (2002) Theory and Practice of Professional Development of Primary and Secondary School Teachers. Jilin People's Publishing House, Changchun.

[7] Liu, W.H. (2003) Teacher Professional Development: Connotation, Problems and Trends. Educational Exploration, No. 12, 103-105.

[8] Zhu, X.D. (2014) On the Theoretical Model Construction of Teacher Professional Development. Educational Research, 35, 81-90.

[9] Opinions on the Establishment of Standards for the Preparation of Faculty and Staff in Primary and Secondary Schools (2001). http://www.gov.cn/gongbao/content/2001/content_61159.htm

[10] Setting Standards for Secondary Vocational Schools (2010). http://www.jyb.cn/info/jyzck/201008/t20100825_384005.html

[11] Qiang, Y. (2011) Comparative Analysis of the Legal Wage of the OECD High School Teachers in 31 Countries. Shanghai Education Research, No. 5, 26-29.

[12] Li, J. and $\mathrm{Hu}, \mathrm{X}$. (2018) Thoughts on the Evaluation Reform of Ordinary High School Teachers under the New College Entrance Examination System. Curriculum Teaching Research, No. 1, 16-19+29.

[13] Yang, X. and Yang, X. (2002) Analysis of Teacher Burnout. Foreign Education Research, No. 2, 56-60.

[14] Hu, H., Liu, L. and Chen, X. (2015) Study on the Status Quo of the Job Burnout of Primary and Secondary School Teachers and Its Influencing Factors. Journal of Northeast Normal University (Philosophy and Social Sciences Edition), No. 3, 233-237.

[15] Jiang, Y. (1999) On the "People-Oriented" School Management Strategy. Modern Education Series, No. 1, 25-29. 